\title{
Behaviour and dynamics of a hydrothermal plume in Lake Banyoles, Catalonia, NE Spain
}

\author{
TERESA SERRA* $\dagger$, MARIANNA SOLER*, RAMON JULIÀ + , XAVIER CASAMITJANA* and \\ JORDI COLOMER*† \\ *Department of Physics, University of Girona, Campus Montilivi, 17071 Girona, Spain (E-mail: \\ teresa.serra@udg.es) \\ $\dagger$ Centre d'Estudis Comarcals de Banyoles, Plaça de la Font, 17820 Banyoles, Spain \\ $\ddagger$ Institut de Ciències de la Terra, Jaume Almera, CSIC. Lluís Solé i Sabarís s/n, 08028 Barcelona, Spain
}

\begin{abstract}
A hydrothermal plume forms in Lake Banyoles, NE Spain, as a result of convection above a springwater-fed suspension cloud ponded on the lake floor. The plume propagates upwards reaching a level of neutral buoyancy from where a turbidity current spreads out laterally. Two-dimensional temperature and particle concentration measurements show the fate of the hydrothermal plume and its associated turbidity current and reveal its seasonal development. Silt particles transported by the plume have been used as tracers to determine the maximum and equilibrium heights of the plume. When the lake is stratified, the vertical transport of sediment is confined to the lake hypolimnion, as the thermocline limits the vertical propagation of the plume. In contrast, when the lake water column is mixed, the plume reaches the surface of the lake. The field measurements have been compared with models for thermal convection from finite isolated sources. Measurements of the flow velocity at the source of the hydrothermal plume (i.e. the rim current velocity) indicate that cold hypolimnetic water is entrained by the plume. Sedimentation rates measured from sediment traps at the zone where the turbidity current develops vary between 10 and $25 \mathrm{~g} \mathrm{~m}^{-2}$ day $^{-1}$, and result from continuous silt particle sedimentation from the turbidity current. Sedimentation rates in traps are higher for stations situated close to the source than those further away $\left(<5 \mathrm{~g} \mathrm{~m}^{-2} \mathrm{day}^{-1}\right)$. Moreover, the results demonstrate that double diffusive sedimentation from the turbidity current was dominant over grain-by-grain settling, causing a mixed distribution of sediments in the region where the turbidity current spreads. The deposition of silt particles could explain the occurrence of silt layers interbedded with biocalcarenites in the littoral zones of the lake and the stratigraphy identified by seismic profiles and cores taken from the lake floor.
\end{abstract}

Keywords Double diffuse sedimentation, plume, sediment cores, thermal convection, turbidity current.

\section{INTRODUCTION}

There are a variety of natural settings where density currents interact with density stratification in the ambient fluid. In pyroclastic volcanic eruptions, for example, convective eruption columns grow vertically until they reach a certain height where they spread laterally as a gravity current sheared by the wind. In lakes, density stratification may cause turbidity currents to form interflows rather than bottom hugging currents (Colomer et al., 2001). In this paper, the development of an unusual hydrothermal plume originating from underground springs on the floor of Lake Banyoles in NE Spain is described. The plume develops above a suspension cloud formed 
by ponding of warm water and entrained sediment above the lake-floor vents. It rises to an equilibrium height before spreading laterally as a mesopycnal turbidity current. The behaviour of the plume and the geometry of the related turbidity current are controlled by the state of lake stratification. Since the initial report of this phenomenon (Colomer et al., 2001), the temporal and spatial distribution of the hydrothermal plume and the dynamics and distribution of the turbidity current and the sediment deposited from it have been characterized and are reported below. Although hydrothermal processes in the atmosphere (Fernando et al., 2001) and ocean (Morawitz et al., 1996; Visbeck et al., 1996) have been described previously, hydrothermal processes like those in Lake Banyoles have not been described before.

A series of field surveys has focused on measuring temperature, oxygen concentration and particle volume concentrations (PVCs) along a transect across the lake (Fig. 1A), with the deployment of sediment traps and sediment coring. Results from field measurements are compared with conceptual models for convection from isolated sources in stratified fluids (Whitehead et al., 1996; Maxworthy, 1997) and the sedimentation of particles from turbidity currents (Sparks et al., 1991).

\section{BACKGROUND AND THE AREA OF STUDY}

Lake Banyoles is situated in Catalonia, NE Spain (Fig. 1A). The lake can be divided into northern and southern lobes, separated by a shallow sill. The lake is of tectono-karstic origin and depressions or basins, classically described as 'flat bottom depressions' (Canals et al., 1990), characterize the lake floor. Six isolated basins are defined (B1-B6, indicated by the boxed areas in Fig. 1A), with B1 and B2 being the largest and deepest (Fig. 1B). Basins B1 and B2 are situated in the southern lobe of the lake with the remainder situated in the northern lobe. Water mainly enters the lake via subterranean springs predominantly in basin B1 (75 m deep), which has the largest discharge and supplies $85 \%$ of the total water input $\left(500 \mathrm{l} \mathrm{s}^{-1}\right)$. The rest of the basins do not have significant discharges except during periods of high precipitation in the recharge area, situated at the North of La Garrotxa (see the black area in the small map of Spain in Fig. 1A), $40 \mathrm{~km}$ to the north-west of the lake (Sanz, 1985). There are also five creeks (all of them situated along the west side of the lake) that discharge into the lake and account for the remainder of the water input (ca 15\%). These creeks are represented by dashed lines in Fig. 1A. The water leaves through five streams at the south-eastern margin of the lake (continuous lines in Fig. 1A). The venting subterranean springs in basin B1 entrain sediments creating a suspension cloud with a sharp upper sediment interface, referred to hereafter as the lutocline. The lutocline is marked by a strong gradient in density that divides the water column into two zones: a V-shaped zone below, and a zone of clearer water above (Fig. 1B). The suspension cloud filling B1 has a vertical thickness of $c a 45 / 50 \mathrm{~m}$, a sediment mass concentration of ca $120 \mathrm{~g} \mathrm{l}^{-1}$ (or $4.8 \times 10^{4} \mu \mathrm{l} \mathrm{l}^{-1}$ ) and a temperature of $c a 19 \cdot 1^{\circ} \mathrm{C}$ (constant from the lutocline down to the lake floor), with only slight deviations measured throughout the year. During field measurements, the lutocline was found to be at a depth that oscillated between $29 \cdot 2$ and $32.0 \mathrm{~m}$, measured by a portable sonar unit. Previous studies report periods of shallower depths (ca $25 \mathrm{~m})$ as a result of high discharges from the underground springs (Canals et al., 1990; Casamitjana \& Roget, 1993; Colomer et al., 2002). Colomer et al. (1998) showed that although there is strong mixing below the lutocline, the turbulent kinetic energy is dampened at the lutocline, which acts as a barrier to the propagation of energy. As a consequence, at the lutocline level, the settling velocity of the suspension of particles is equal to the mean upward velocity.

Although a sediment suspension is always developed below the lutocline in basin B1, sedi-

Fig. 1. (A) Schematic map showing the location of Lake Banyoles. The small dark region marked on the map corresponds to the recharge area of the lake (Garrotxa region). Bathymetric map of Lake Banyoles constructed from echo-sounding profiles (Moreno-Amich \& García-Berthou, 1989). Depth contours are in metres. On the western side of the lake, five inlet streams are identified (discontinuous lines). Water leaves the lake through five small rivers situated at the south-eastern edge of the lake (continuous lines). Basins on the floor of the lake are identified by boxes (B1-B6), with B1 and B2 situated in the Southern lobe and B3, B4, B5 and B6 in the Northern lobe. White dots represent measurement sites (S1-S6) and ST1, ST2 and ST3 are the stations where sediment traps were deployed. Two cores, indicated by the large white squares, were retrieved from the southern (C2) and northern lobes (C1). (B) South to North seismic transect (location shown in A) from basin B1 to basin B2 (from Canals et al., 1990). 
A

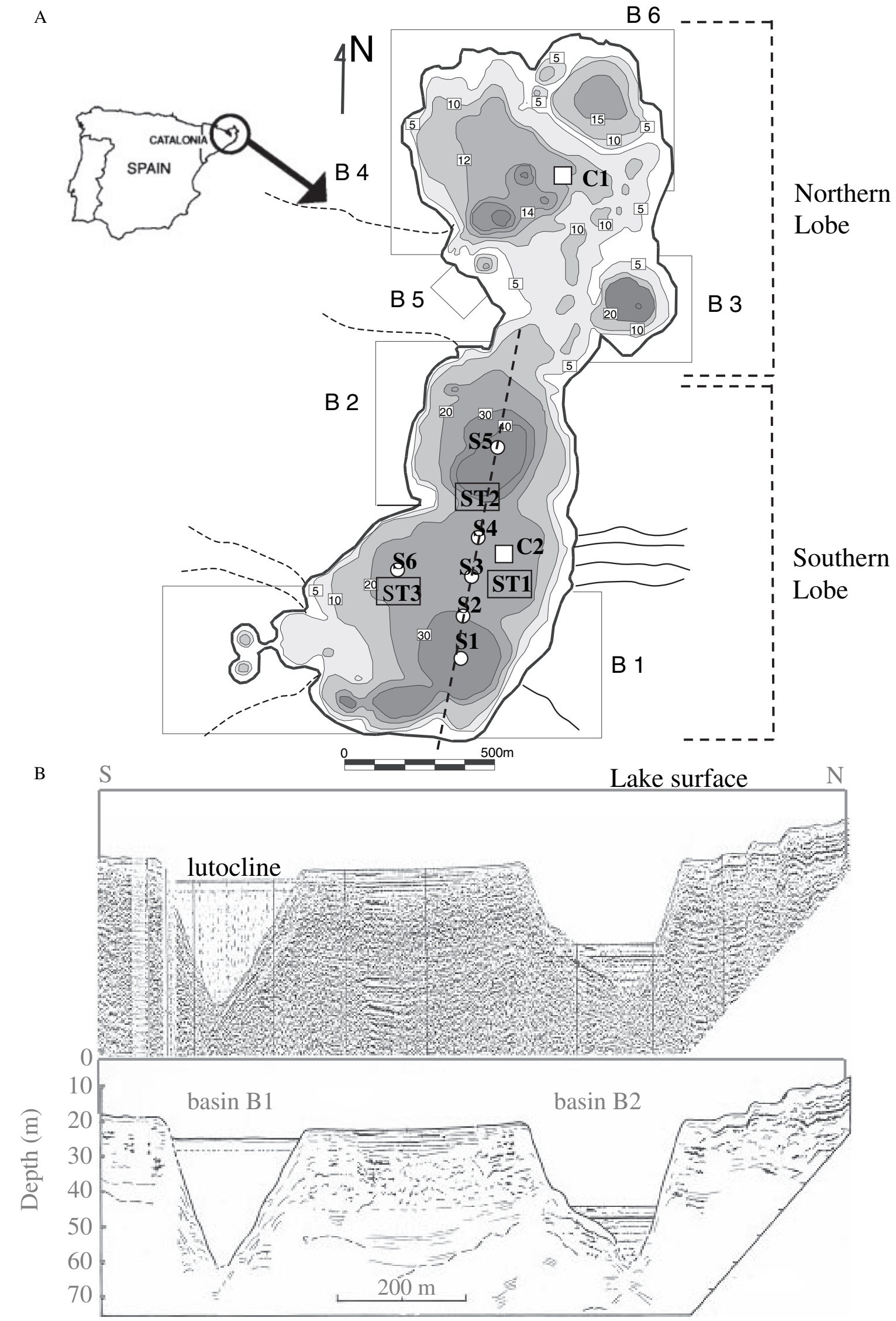

B

(C) 2005 International Association of Sedimentologists, Sedimentology, 52, 795-808 
ments in basin B2 normally remain unsuspended with a flat basin floor at a depth of $44 \mathrm{~m}$ (Fig. 1B). Also, seismic profiles demonstrate the accumulation of stratified lacustrine sediments at the bottom of the lake between basins B1 and B2 and on the floor of basin B2. Colomer et al. (2001) reported the first observation of a plume above basin B1. They pointed out that the difference of temperature between the lutocline and the water above it drives the hydrothermal plume. They described both vertical ( $c a 18 \mathrm{~m}$ height) and horizontal ( $\mathrm{ca} 300 \mathrm{~m}$ wide) scales of the convective zone from PVC measurements.

\section{METHODS}

Seven field surveys were undertaken between July 1998 and July 2000 along the main axis of the lake. Measurements were taken at six stations (S1-S6, Fig. 1A). In these surveys (Table 1) measurements of temperature, oxygen concentration, particle size distribution (PSD) and PVC were taken at different depths in the water column. Flow velocities were also measured at four points around the lutocline in B1. In July 2000, water samples, sediment traps and sediment cores were also taken at selected stations (Fig. 1A).

Both PSD and PVC were measured with an in situ laser particle size analyzer (LISST-100; Sequoia Inc.). The LISST-100 measures particles with diameters ranging from 1.25 to $200 \mu \mathrm{m}$. In addition, it measures the depth by means of a pressure sensor, with a resolution of $5 \mathrm{~cm}$. Temperature and oxygen concentrations were measured with a multiparametric probe (HydroLab). The temperature was measured with a resolution of $0.01{ }^{\circ} \mathrm{C}$ and an accuracy of $0.04{ }^{\circ} \mathrm{C}$, and the oxygen concentration was measured with an accuracy of $0.2 \mathrm{mg} \mathrm{l}^{-1}$. Measurements of the velocity and flow direction were carried out with an electromagnetic current meter (ACM-8M; Alec Instruments). This instrument measures the horizontal component of the water velocity and the flow direction. Experimental errors for the measurements of velocities and direction are $2 \%$ and $2^{\circ}$, with resolutions of $0 \cdot 1 \mathrm{~cm} \mathrm{~s}^{-1}$ and $0 \cdot 2^{\circ}$, respectively.

Five-litre samples of water were taken at different depths at station S1 (in basin B1) and analysed in the laboratory in order to determine the nature of the particles (organic or inorganic). Samples were filtered in glass-fibre filters, dried and later heated with a muffle furnace at $500{ }^{\circ} \mathrm{C}$ (following the procedure detailed by Kristensen \& Andersen, 1987). From the difference between the mass of the samples before and after being heated, the amount of organic matter could be quantified. Three sediment trap arrays (ST1, ST2 and ST3) were deployed in the region between basins B1 and B2 (Fig. 1A) and replaced after 5 days. Each sediment trap array consisted of four traps located at depths of $8,12,15$ and $19 \mathrm{~m}$, with three replicates in each trap. In this study, the sedimentation rates refer to the total amount of material accumulated in the trap. Finally, two sediment cores were collected with a non-commercial coring device borrowed from the Jaume Almera Institute of Earth Science in Barcelona. The first core was taken from the northern lake lobe (C1, Fig. 1A) and the second from a zone between basins $\mathrm{B} 1$ and $\mathrm{B} 2$ in the southern lobe (C2, Fig. 1A). The device has a piston inside a plastic casing, $63 \mathrm{~mm}$ in diameter and $3 \mathrm{~m}$ long, and was pushed down into the sediment from a raft. The sediment cores obtained were split longitudinally and placed in cold storage at $2{ }^{\circ} \mathrm{C}$ for description and sampling. The cores were imaged using a CCD camera for grey-scale analyses.

Table 1. The maximum height of the column $(H)$ at basin B1 (from the lutocline up to the surface of the lake), experimental values for the maximum height $\left(h_{\max }\right)$ and equilibrium height $\left(h_{\mathrm{eq}}\right)$ reached by the plume, and the depth of the base of the thermocline $\left(z_{\mathrm{T}}\right)$. The last column of the table shows whether or not the plume is constrained and if it is, the factor that limits its vertical development.

\begin{tabular}{llllll}
\hline Field campaign & $H(\mathrm{~m})$ & $h_{\mathrm{eq}}(\mathrm{m})$ & $h_{\max }(\mathrm{m})$ & $z_{\mathrm{T}}(\mathrm{m})$ & Constrained \\
\hline July 1998 & $28 \cdot 7$ & $13 \cdot 7$ & $17 \cdot 7$ & 10 & No \\
September 1998 & $29 \cdot 9$ & $9 \cdot 9$ & $12 \cdot 9$ & 14 & No \\
February 1999 & 30 & 30 & 30 & - & Surface \\
July 1999 & 31 & 20 & 21 & 10 & Thermocline \\
March 2000 & $32 \cdot 5$ & $18 \cdot 5$ & $19 \cdot 5$ & 14 & Thermocline \\
April 2000 & 32 & 16 & 20 & 14 & Thermocline \\
July 2000 & 29 & 14 & 20 & 10 & Thermocline
\end{tabular}




\section{RESULTS}

\section{Development of the hydrothermal plume above the lutocline in basin B1}

In March 2000, the water column was weakly stratified, as can be seen from the temperature profile measured (Fig. 2). The epilimnion extended from the surface to a depth of $8 \mathrm{~m}$, the thermocline had a vertical thickness of $5 \mathrm{~m}$ and the hypolimnion extended down to a depth of

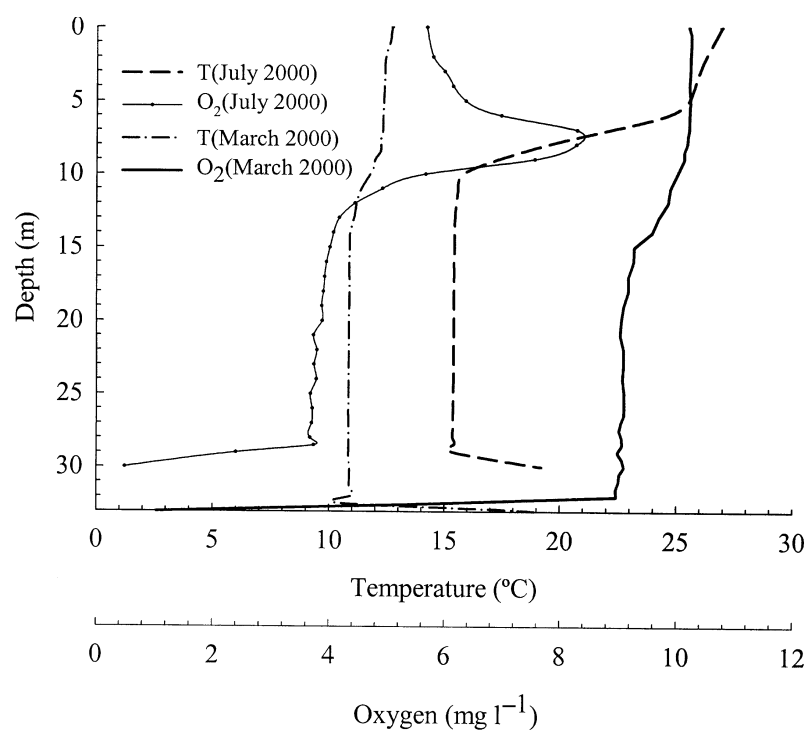

Fig. 2. Temperature and oxygen concentration vertical profiles for the surveys carried out in March 2000 and July 2000 at S1 (see Fig. 1).
$32.5 \mathrm{~m}$ (Fig. 2). At this depth, the temperature increased to $19 \cdot 1^{\circ} \mathrm{C}$ indicating the presence of the warm lutocline. When the stratification was completely developed, as in July 2000, the epilimnion was considerably warmer than the hypolimnion (Fig. 2). In July 2000, the welldeveloped epilimnion extended from the surface down to $5 \mathrm{~m}$ depth, the thermocline had a vertical thickness of about $5 \mathrm{~m}$, and the hypolimnion below extended down to $29.0 \mathrm{~m}$ depth (Fig. 2). In July 2000, a peak in oxygen concentration was found at the thermocline layer, which coincided with the development of an algal bloom (Fig. 2). This was corroborated with observations of the samples under the microscope and it coincided with an increase in the PVC measured in situ.

Due to the difference between the temperature of the lutocline and the hypolimnetic water immediately above, an upward-directed hydrothermal plume develops (Colomer et al., 2001). This plume carries a suspension of particles from the lutocline level up to a maximum height $\left(h_{\max }\right)$. The maximum height was found to vary in each field survey carried out (see Table 1), and was dependent on the stratification of the water column. During overturn (November-March), the PVC in the water column was lower, ca 2-3 $\mu \mathrm{l}^{-1}$ (see the February 1999 PVC profile at station S1 in Fig. 3A) than it was in the stratified period, from April to October, ca 4-5 $\mu \mathrm{l} \mathrm{l}^{-1}$ (see the September 1998 PVC profile at S1 in Fig. 3A, the July 1999 PVC profile at $\mathrm{S} 1$ in Fig. $3 \mathrm{~B}$ and the April and
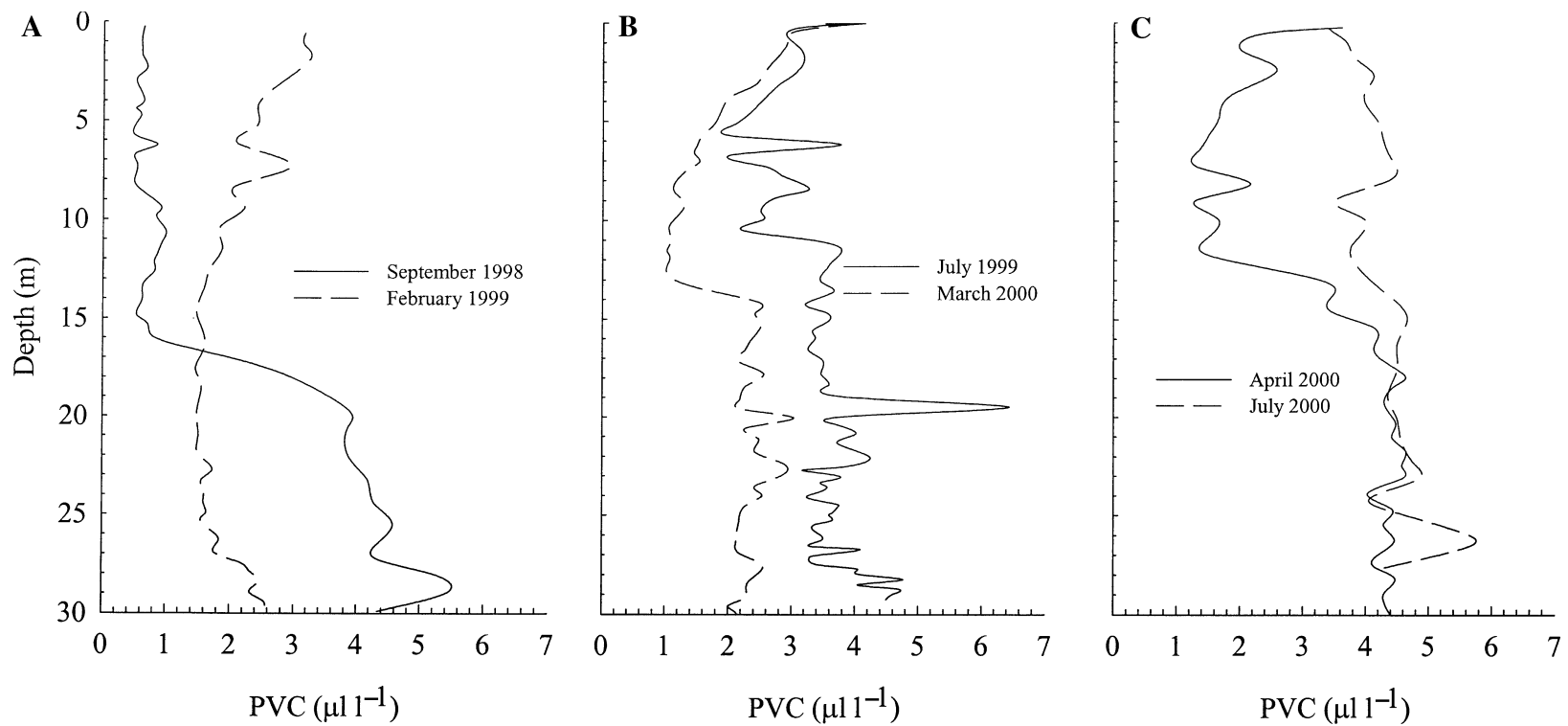

Fig. 3. PVC profiles at the centre of basin B1 for the surveys carried out in September 1998 and February 1999 (A), July 1999 and March 2000 (B) and April 2000 and July 2000 (C).

(C) 2005 International Association of Sedimentologists, Sedimentology, 52, 795-808 
June 2000 PVC profiles at S1 in Fig. 3C). In September 1998 (Fig. 3A), the hydrothermal plume identified in basin B1 carried a suspension of particles, with PVC values of $c a 4-5 \mu \mathrm{l} \mathrm{l}^{-1}$, immediately above the lutocline up to a depth of $20 \mathrm{~m}$. Here the PVC decreased towards the surface to about $0.5 \mu \mathrm{l} \mathrm{l}^{-1}$ at a depth of $16 \mathrm{~m}$, corresponding to the top of the hydrothermal plume. For the PVC measurements carried out during the mixed period, the plume was found to reach the surface of the lake, as was found in the February 1999 survey (Fig. 3A; Table 1). For the surveys in July 1999, March 2000, April 2000 and July 2000, the plume reached the base of the thermocline (Table 1), whereas in September 1998, the plume had its minimum vertical development, rising only $c a 10 \mathrm{~m}$ above the lutocline.

Samples collected at a depth of $10 \mathrm{~m}$ in July 2000, where the algal bloom was detected (Fig. 3C), were composed of 50\% organic matter and $50 \%$ inorganic matter. Analysis of samples from greater depths showed that the percentage of inorganic matter increased with depth and at $c a$ $15 \mathrm{~m}$ depth, inside the zone occupied by the plume, the mass concentration was $95 \%$ inorganic matter and $5 \%$ organic. The composition remained constant from a depth of $15 \mathrm{~m}$ down to the lutocline. Also, there was no variation in the dissolved oxygen concentration (as shown in Fig. 2). Therefore, the signal obtained by the laser analyzer is attributed to inorganic particles advected from the lutocline in basin B1. Samples of water obtained at $15 \mathrm{~m}$ depth were observed under the scanning electron microscope and these showed that the sediments were mainly composed of inorganic silts.

The flow velocity was measured at four stations (SN, SW, SS and SE) situated along the periphery of basin B1 (Fig. 1A), at a depth close to the lutocline ( $c a 28 \pm 1 \mathrm{~m}$ depth, Fig. 4), during the February and July 1999, and March and April 2000 surveys (Fig. 4). Flow velocity was measured for $4 \mathrm{~min}$ at a frequency of $0.5 \mathrm{~Hz}$. No significant differences were obtained between velocities measured in the mixing period compared with those measured in the stratified period of the lake, and the mean flow velocity obtained over the whole data set was $3 \cdot 2 \pm 0.4 \mathrm{~cm} \mathrm{~s}^{-1}$. The flow direction was always directed towards the base of the plume indicating entrainment of cold water from the periphery to the plume base.

\section{The development of the turbidity current between basin $\mathrm{B} 1$ and $\mathrm{B2}$}

As the hydrothermal plume entrains water, the buoyancy of the plume should decay upward from the source. At the equilibrium height $\left(h_{\mathrm{eq}}\right)$, the density within the plume equals the background density and a particle-laden gravity current spreads out horizontally as a mesopycnal turbidity current (Mulder \& Alexander, 2001). At the end of the lake stratification period (September), the turbidity current was found to spread along the region between $\mathrm{B} 1$ and $\mathrm{B} 2$ as can be observed from the PVC profile in Fig. 5. PVC values are large at the bottom $c a 3 \mu \mathrm{l}^{-1}$ at $22 \mathrm{~m}$ depth decreasing to $1 \mu \mathrm{l}^{-1}$ at $15 \mathrm{~m}$ depth. In
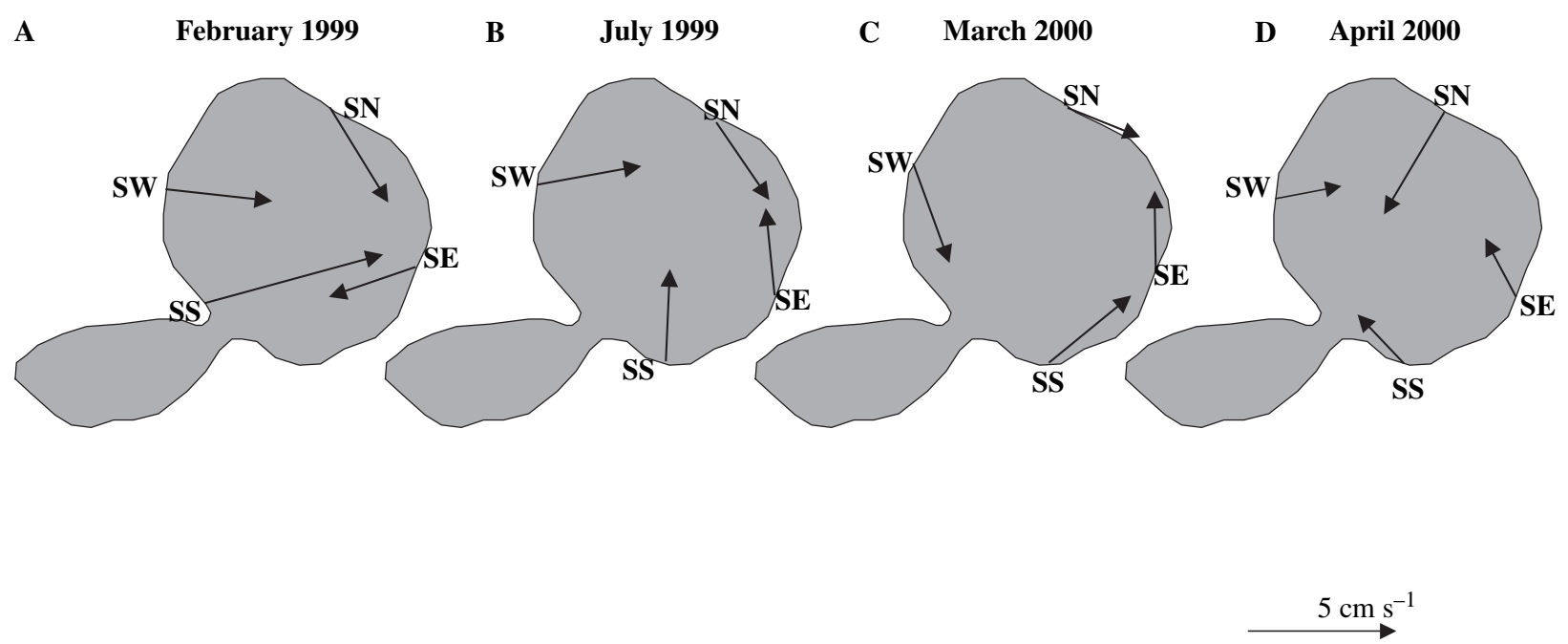

Fig. 4. Flow velocity at $h \sim 1 \mathrm{~m}$ above the source of the plume (in B1). Velocities were measured at four stations (around the lutocline) and for four of the survey periods: February 1999 (A), July 1999 (B), March 2000 (C) and April 2000 (D). Velocity vectors are plotted on the $30 \mathrm{~m}$ depth contour surrounding basin B1 (Fig. 1A). 


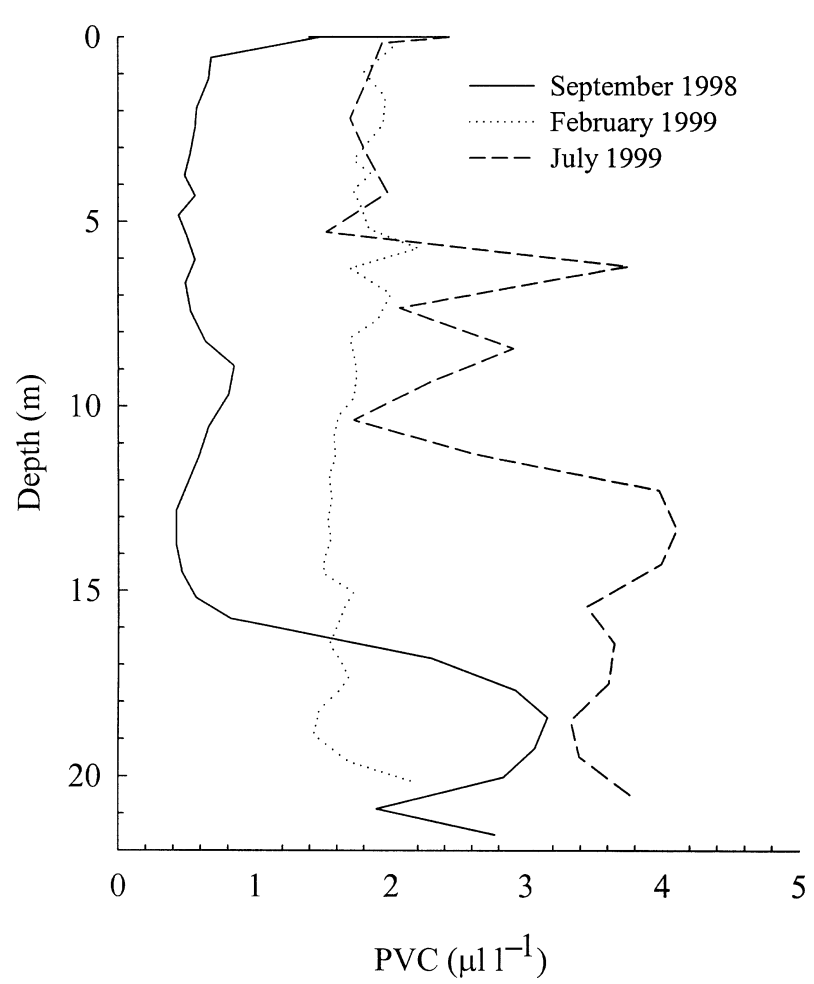

Fig. 5. PVC at station S4 between basins B1 and B2 for the surveys carried out in September 1998, February 1999 and July 1999.

contrast, in the winter profile (February 1999) the PVC was nearly constant and lower, ca $1 \cdot 7 \mu \mathrm{ll}^{-1}$, as a result of lake mixing, and extended throughout the whole water column. In July 1999, the PVC profile was nearly constant from the bottom up to a depth of $12 \mathrm{~m}, \mathrm{ca} 4 \cdot 2 \mu \mathrm{l} \mathrm{l} \mathrm{l}^{-1}$, and decreased thereafter as the surface of the lake was approached (Fig. 5). In the July 1999 profile, the peaks between 5 and $10 \mathrm{~m}$ were attributed to an algal population. The extension of the turbidity current is revealed in the longitudinal (southnorth) contour maps of PVC for stations between basin B1 (situated on the left of the transect figure, Fig. 6) and basin B2 (situated on the right of the transect figure, Fig. 6) for the surveys carried out in June 1999 (Fig. 6A), March 2000 (Fig. 6B), July 2000 (Fig. 6C) and September 1998 (Fig. 6D). Whereas the largest PVC values were found for stations close to the source (in basin B1), the PVC values were still significant upon reaching basin B2 despite the loss of particles between the two basins. The largest vertical and horizontal extents of the plume were found for periods of weak and medium stratification of the lake, as can be observed from the July 1999 (Fig. 6A), March 2000 (Fig. 6B) and July 2000 (Fig. 6C) surveys, whereas the smallest horizontal and vertical extents were found during periods of strong stratification, such as the case in September 1998 (Fig. 6D). The maximum height reached by the plume has been highlighted in each contour map as a black horizontal straight line. Again, from the analysis of the samples collected from the water column, the PVC peaks in July 1999 and July 2000 measured with the LISST-100 within the thermocline layer were attributed to an algal population.

In addition, the PSD inside the plume is different to that outside the plume (Fig. 7A and B). The PSD has a bimodal shape for depths inside the plume (Fig. 7A), with peaks centred at 10 and $50 \mu \mathrm{m}$-diameter, i.e. in the silt particle range. Outside the plume, and usually coinciding with depths within the epilimnion layer, the PSD shows a trimodal distribution (Fig. 7B), with particles centred at 5, 18 and $50 \mu \mathrm{m}$ in diameter. Particles transported by the plume are thus larger than those found by Walker \& Baker (1988) in a hydrothermal plume on the Juan de Fuca Ridge, where particles had diameters smaller than $2 \mu \mathrm{m}$. At the thermocline layer, the PSD has an intermediate character (PSD data not shown). Scanning electron microscope photographs of the samples collected from the hypolimnion (data not shown) and from below the lutocline level showed similar appearances, with the presence of silts. Sediment particles from the hypolimnion are transported from the lutocline level through the lake hypolimnion by the hydrothermal plume and later on by the mesopycnal turbidity current. Sediment trap results (Table 2) also demonstrate that traps located closer to the hydrothermal plume in basin B1 (ST1 and ST3) receive higher particle sediment fluxes $\left(10-25 \mathrm{~g} \mathrm{~m}^{-2}\right.$ day $\left.^{-1}\right)$ compared with the low values received by ST2 $\left(<5 \mathrm{~g} \mathrm{~m}^{-2}\right.$ day $\left.^{-1}\right)$, near basin B2.

The two cores extracted from the lake showed important differences. Core C1 (Fig. 8A) was extracted from the northern lobe (Fig. 1A) of the lake, in shallow water (9 $\mathrm{m}$ depth). This core consists of thin bedded to laminated bluish grey (5BG 6/1) carbonate lutites, and light bluish grey (5BG 7/1) bioclastic sands with a mud matrix. The skeletal grains are composed of abundant encrusted charophyte stems, and sparse gastropods and ostracods. Core C2 (Fig. 8B) was taken from the southern lobe of the lake (Fig. 1A) in water $20 \mathrm{~m}$ deep. The sediments here consist of massive bioturbated light grey (10Y 7/2) carbonate lutites with occasional interbedded thin light grey $(7 \cdot 5 \mathrm{Y}$ 7/1) layers. These muddy sediments contain abundant gas bubbles. 

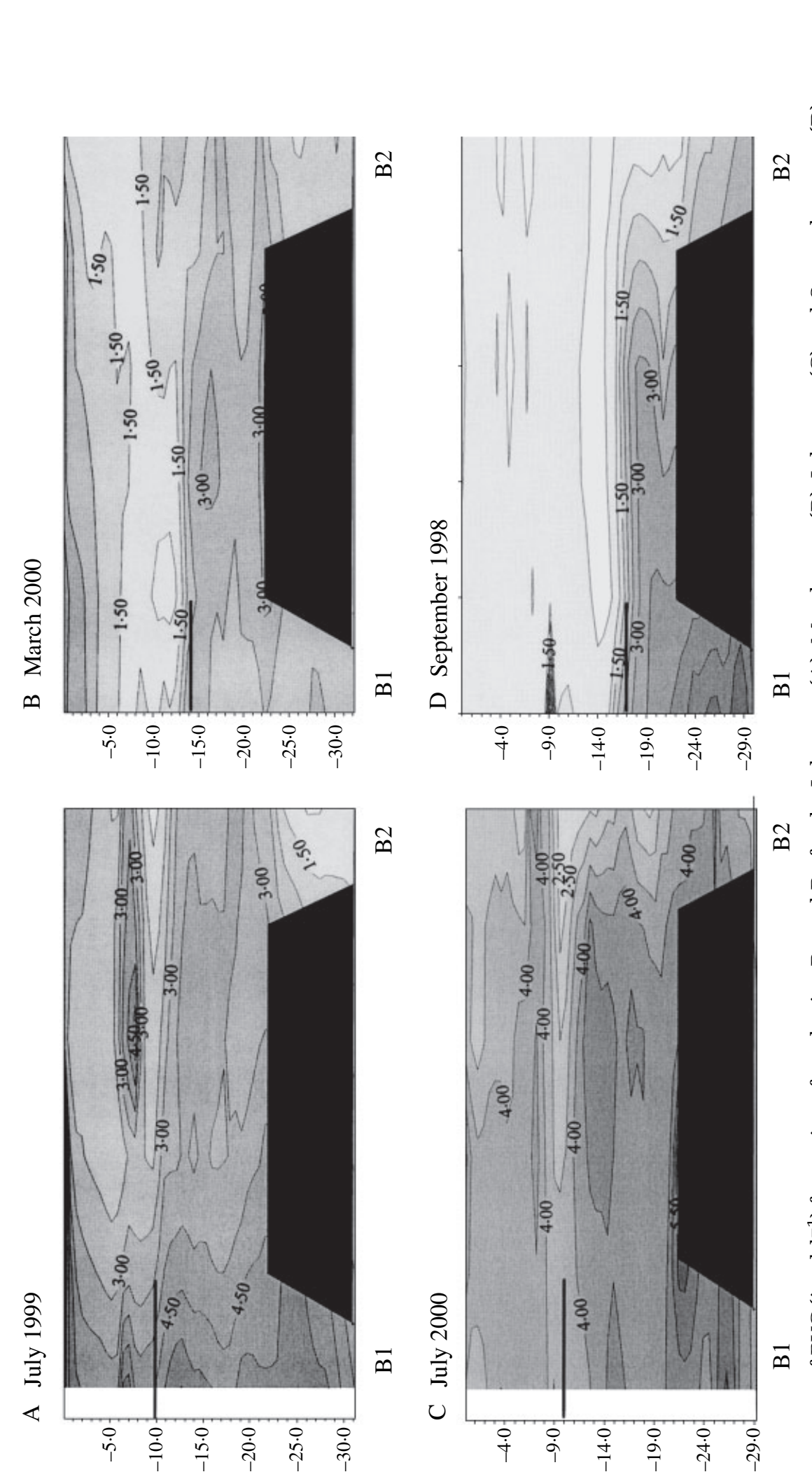

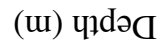

$$
\text { (ய) чาฮㅁ }
$$

के

巨ิ

$\infty$

है

范

옹

를

ติ

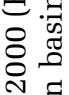

고

空

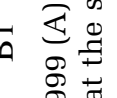

吾范

Ð

๗)

要

ติ ฮ

주웡

$\vec{\varphi} \Phi$

द

承

켸

욤

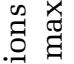

吾

की

I

三 원

$\exists \underset{\Xi}{\Xi}$

$\bar{n}$ 点:

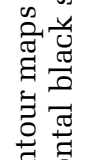

نี

일 

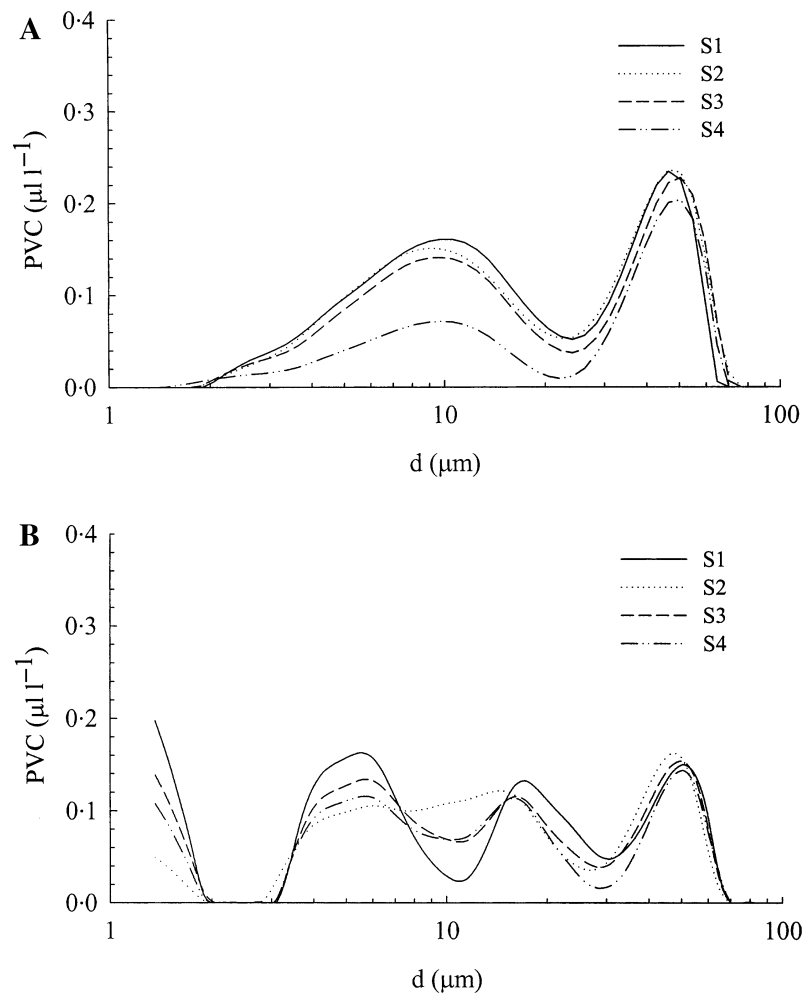

Fig. 7. PSD for the July 2000 survey for the different stations considered and for hypolimnetic waters, with $z=17 \mathrm{~m}$ depth (A), and for epilimnetic waters, $z=4 \mathrm{~m}$ depth (B), at different stations along the southnorth axis of the lake.

Table 2. Results obtained from the sediment traps (ST1, ST2 and ST3; $\mathrm{g} \mathrm{m}^{-2} \mathrm{day}^{-1}$ ) for the different depths studied.

\begin{tabular}{cllr}
\hline$z(\mathrm{~m})$ & ST1 & ST2 & \multicolumn{1}{c}{ ST3 } \\
\hline 8 & $10 \cdot 4 \pm 2 \cdot 8$ & $4 \cdot 2 \pm 0 \cdot 2$ & $5 \cdot 2 \pm 0 \cdot 1$ \\
12 & $13 \cdot 3 \pm 4 \cdot 1$ & $3 \cdot 1 \pm 0 \cdot 2$ & $15 \cdot 9 \pm 7 \cdot 3$ \\
16 & $14 \cdot 2 \pm 3 \cdot 1$ & $4 \cdot 4 \pm 0 \cdot 2$ & $5 \cdot 7 \pm 0 \cdot 2$ \\
19 & - & $5 \cdot 3 \pm 0 \cdot 2$ & $23 \cdot 9 \pm 8 \cdot 6$ \\
\hline
\end{tabular}

\section{DISCUSSION}

Assuming that the plume is in quasi-steady state and that buoyant forces dominate over momentum from very short distances above the source, several non-dimensional numbers describe the system when the stratification and the size of the forcing region (the lutocline) are specified (Maxworthy \& Narimousa, 1994; Whitehead et al., 1996; Maxworthy, 1997). First, the non-dimensional number $N / f$ compares the relative significance between stratification (through $N$, the stratification parameter) and rotation (through $f$, the Coriolis parameter). The Brünt-Väisälä frequency $(N)$ can be calculated using $N=(g \alpha \Delta T)$ $\Delta z)^{1 / 2}$, where $\alpha$ is the thermal expansion coefficient for water. For the case in hand, $N / f$ ranges from 17 (corresponding to a very weak stratification in February) to 61 (corresponding to a strong summer lake stratification). In all cases, $N / f$ is large enough for the stratification of the water column to dominate over rotation. Secondly, the non-dimensional aspect ratio of the plume $\left(A_{\mathrm{p}}\right)$ is defined as the ratio between the vertical maximum height of the plume $\left(h_{\max }\right)$ and the horizontal source diameter $(D \sim 300 \mathrm{~m}$, Fig. 1A). In the present case, $A_{\mathrm{p}}=h_{\max } / D$ ranges from 0.043 to $0 \cdot 10$, which corresponds to the range of plumes with low aspect ratios (Fernando et al., 2001). Examples of large $A_{\mathrm{p}}$ are found in point-plume sources, whereas examples of low-aspect ratios are found in geophysical applications, such as urban heat islands $\left(A_{\mathrm{p}} \sim 0 \cdot 06\right.$, Lu et al., 1997), Central Labrador deep ocean convection ( $A_{\mathrm{p}} \sim 0.01$, Sy et al., 1997), Gulf of Lion deep ocean convection $\left(A_{\mathrm{p}} \sim 0 \cdot 02-0 \cdot 03\right.$, Gaillard \& Desaubies, 1997) and the Juan de Fuca Ridge megaplume $\left(A_{\mathrm{p}} \sim 0.05\right.$, Baker et al., 1987). Therefore, the plume described here has similar characteristics to ocean plumes and to laboratory experiments of convection driven by localized sources. Finally, the Rossby plume number $R_{\mathrm{o}}^{*}=\left(B_{\mathrm{o}} / f^{3} h_{\mathrm{o}}^{2}\right)^{1 / 2}$ (where $B_{\mathrm{o}}$ is the total buoyancy flux per unit area and $h_{\mathrm{o}}$ is the length scale of convection) determines whether the plume develops a single vortex column around it or whether it develops several vortices (Maxworthy \& Narimousa, 1994). The total buoyancy flux can be calculated by using $B_{\mathrm{o}}=w_{\mathrm{o}}\left(\rho-\rho_{\mathrm{o}}\right) g / \rho_{\mathrm{o}}$, where $w_{\mathrm{o}}$ is the vertical velocity of the fluid, $g$ is the gravitational constant and $\rho$ and $\rho_{\mathrm{o}}$ are the densities of the water discharge and the background fluid, respectively. Based on the maximum height to which the hydrothermal plume can rise, $R_{\mathrm{o}}^{*}$ was always found to be larger than the critical $R_{\mathrm{oc}}^{*}=3$ (see Table 3) and corresponds to the range where a convective plume develops a single vortex column (Narimousa, 1996).

The most important quantities that characterize the plume structure are the maximum height $\left(h_{\max }\right)$ to which the plume migrates and the equilibrium height $\left(h_{\mathrm{eq}}\right)$, at which the plume spreads laterally. Laboratory experiments of convection from finite diameter isolated sources in rotating domains have been carried out to determine both $h_{\max }$ and $h_{\text {eq }}$ (Whitehead et al., 1996; Maxworthy, 1997) as a function of the character- 

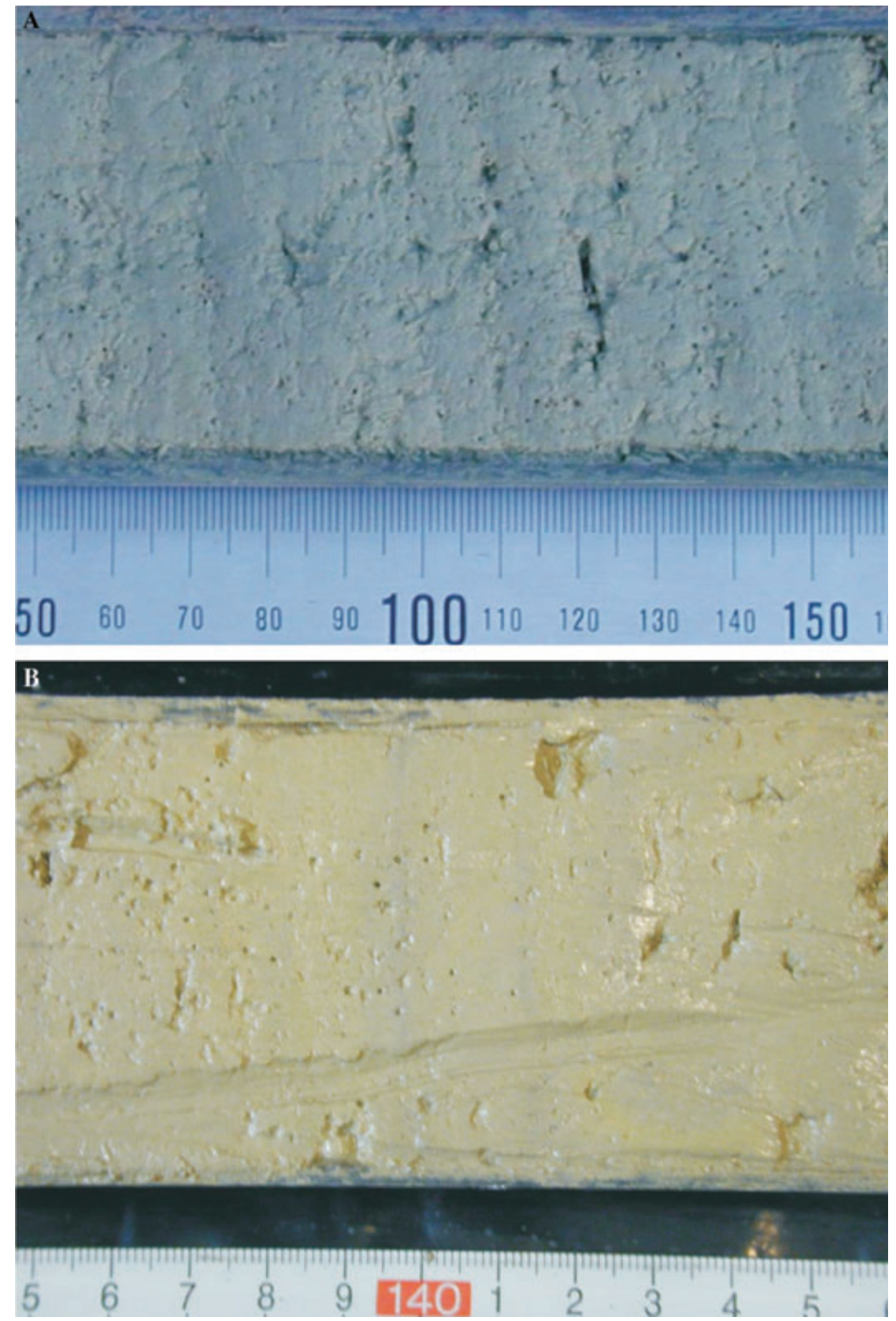

Fig. 8. Photographs of the cores $\mathrm{C} 1$ (A) and C2 (B) obtained from the northern and southern lobes of the lake, respectively. istics of the source $\left(D, B_{0}\right)$, the stratification of the water column $(N)$ and the rotation rate $(f)$. Assuming a linear stratification of the water column, the maximum height of the plume predicted by these models is determined by the height at which the plume is arrested by lateral buoyancy flux due to baroclinic eddies, i.e.

$$
h_{\max }=3 \cdot 7\left(B_{0} D\right)^{1 / 3} / N,
$$

where the value 3.7 is obtained from laboratory experiments (Whitehead et al., 1996). Other studies show that $h_{\mathrm{eq}} / h_{\max }=0.694$ (Lu et al., 1997), in which case the plume reaches its level of neutral buoyancy and spreads laterally at a height,

$$
h_{\mathrm{eq}}=2 \cdot 6\left(B_{0} D\right)^{1 / 3} / N .
$$

The number of vortices that are formed by the baroclinic instability (Whitehead et al., 1996) can be calculated by using,

$$
N_{\mathrm{v}}=0 \cdot 7\left(D^{2} / B_{\mathrm{o}}\right)^{1 / 3} f,
$$

and the flow velocity at the source, known as the rim current scales as (Legg, 1996)

$$
v=N h_{\max } \cdot
$$


Table 3. Total buoyancy $\left(B_{\mathrm{o}}\right)$, Brünt-Väisälä frequency $(N)$, maximum depth of the column $(H)$, maximum height $\left(h_{\max }\right)$ and equilibrium height $\left(h_{\mathrm{eq}}\right)$ of the plume predicted from the models (Equations 1 and 2$)$, number of eddies $\left(N_{\mathrm{v}}\right.$, see Eq. 3), Rossby number $\left(R_{\mathrm{o}}^{*}\right)$ of the plume, the non-dimensional frequency $(N / f)$ and the Richardson number $\left(R_{\mathrm{i}}\right)$ for the different surveys carried out (July 1998, September 1998, February 1999, July 99, March 2000, April 2000 and July 2000). The second last row of the table refers to the rim velocity calculated from the model (Eq. 4). For the calculation, the experimental value of the maximum height reached by the plume was considered (see Table 1). The last row of this table refers to the values of the rim velocity measured by the electromagnetic current meter.

\begin{tabular}{lccccccc}
\hline & July 1998 & September 1998 & February 1999 & July 1999 & March 2000 & April 2000 & July 2000 \\
\hline$B_{\mathrm{o}}\left(\times 10^{-7}\right)\left(\mathrm{cm}^{2} \mathrm{~s}^{-3}\right)$ & $0 \cdot 4$ & $0 \cdot 2$ & $1 \cdot 3$ & $0 \cdot 4$ & $0 \cdot 6$ & $0 \cdot 9$ & $0 \cdot 4$ \\
$N\left(\times 10^{-3}\right)\left(\mathrm{s}^{-1}\right)$ & $4 \cdot 4$ & $5 \cdot 9$ & $1 \cdot 7$ & $2 \cdot 9$ & $1 \cdot 7$ & $2 \cdot 7$ & $3 \cdot 6$ \\
$H(\mathrm{~m})$ & $28 \cdot 7$ & $29 \cdot 9$ & 30 & 31 & $32 \cdot 5$ & 32 & 29 \\
$h_{\mathrm{max}}(\mathrm{m})$ & $18 \cdot 4$ & $10 \cdot 3$ & 72 & 24 & $56 \cdot 4$ & 30 & 24 \\
$h_{\mathrm{eq}}(\mathrm{m})$ & $11 \cdot 5$ & $7 \cdot 2$ & 50 & 17 & $39 \cdot 6$ & $21 \cdot 3$ & 17 \\
$N_{\mathrm{v}}$ & $0 \cdot 9$ & $1 \cdot 1$ & $0 \cdot 6$ & $0 \cdot 9$ & $0 \cdot 7$ & $0 \cdot 7$ & $0 \cdot 8$ \\
$R_{\mathrm{o}}^{*}$ & $10 \cdot 6$ & $12 \cdot 8$ & $5 \cdot 2$ & $9 \cdot 0$ & $4 \cdot 6$ & $10 \cdot 1$ & $9 \cdot 1$ \\
$N / f$ & 45 & $60 \cdot 5$ & 17 & $29 \cdot 7$ & $17 \cdot 4$ & $27 \cdot 7$ & 37 \\
$R_{\mathrm{i}}$ & 194 & 517 & 30 & 102 & 12 & 10 & 591 \\
$V\left(\mathrm{~cm} \mathrm{~s}^{-1}\right)$ (Eq. 4) & $7 \cdot 8$ & $7 \cdot 6$ & $5 \cdot 1$ & $6 \cdot 1$ & $3 \cdot 3$ & $5 \cdot 4$ & $7 \cdot 2$ \\
$V\left(\mathrm{~cm} \mathrm{~s}^{-1}\right.$ ) (measured) & - & - & $3 \cdot 5 \pm 0 \cdot 4$ & $3 \cdot 3 \pm 0 \cdot 3$ & $3 \cdot 4 \pm 0 \cdot 5$ & $2 \cdot 7 \pm 0 \cdot 5$ & - \\
\hline
\end{tabular}

Taking into consideration the experimental values of $B_{\mathrm{o}}, N$ and $D$ then $h_{\mathrm{max}}, h_{\mathrm{eq}}$ and $N_{\mathrm{v}}$ are obtained from (1), (2), (3) and (4), respectively (see Table 3 for results). During the period of lake mixing (February) and the onset of the lake stratification (March-July) the calculated $h_{\max }$ is found to be larger than the water column in which the plume could develop, so the plume collapses at the water surface or at the base of the seasonal thermocline, in accordance with the results from the PVC profiles, that show constant PVC values up to the base of the thermocline. In these cases, the vertical development of the plume was physically constrained by the lake surface or by the thermocline. In July and September 1998, $h_{\max }$ was found to be $18 \cdot 4$ and $10 \cdot 3 \mathrm{~m}$, respectively, and these depths are consistent with the measured $h_{\max }$, at $17 \cdot 7$ and $12.9 \mathrm{~m}$, respectively (Tables 1 and 3). In September 1998, the strong stratification forced the plume to remain in a thin bottom layer (Fig. 3A). According to these results, both $h_{\max }$ and $h_{\text {eq }}$ collapse during the period of lake mixing and the onset of the stratification, whereas in both the July and September 1998 surveys, $h_{\text {eq }}$ was found to separate from $h_{\max }$ (Table 1). In addition, in these months $h_{\text {eq }}$ was calculated to be at a height of 11.5 and $7.2 \mathrm{~m}$. These calculated values deviate slightly from the values measured for $h_{\text {eq }}$ of $13 \cdot 7$ and $9.9 \mathrm{~m}$ from the surface, respectively. As expected for the calculated Rossby numbers $\left(R_{0}^{*}\right)$ for the plume, the number of vortices approximates 1 for all the surveys (Table 3). Due to the horizontal shape of the lake, this single vortex is forced to travel to the north of the lake as a turbidity current. This result is in accordance with the results of Dewar (2002) who demonstrated that topography in the Gulf of Lion (in the Mediterranean Sea) significantly modifies the evolution of convective plumes occurring over the sea floor. The fact that the horizontal extension of the turbidity current is at its smallest in September 1998 may be due to the fact that the buoyancy flux $\left(B_{0}\right)$ is also at a minimum (Table 3 ).

In general, the rim current velocities predicted by the model (Eq. 4) deviate from the values of the flow velocity measured around the source (Table 3). The largest difference found is for the April 2000 and July 1999 surveys, where experimental values are half the values predicted by the model. For the March 2000 survey, calculated values predict satisfactorily the experimental values measured. These differences are attributed to two main causes. First, velocities might not be completely horizontal because of the V-shaped topography around the source in basin B1. It must be pointed out that Eq. 4 was derived for open convection from an isolated source without boundary constraints. The V-shape of the depressions (Fig. 1B) might play a crucial role in determining the rim velocity and its direction. In the situation under study, the water already present in the basin can be entrained by the hydrothermal plume. Secondly, in some cases the thermocline or the surface of the lake stops the vertical development of the plume. In such situations, the plume is not completely developed in the vertical direction and for the calculation of $v, h_{\max }$ has been considered to be the measured value of the maximum height reached by the plume rather than that 
predicted by the model (Eq. 1). Therefore, more laboratory experiments need to be performed in order to develop a model that describes the rim velocities in a confined source and under conditions of vertical constriction of the plume.

Measurement of particle concentrations (Fig. 6A-C; Table 1) demonstrate that the plume did not penetrate through the thermocline. These results are in accordance with the experimental results by Narimousa (1996) for the penetration of plumes through density interfaces. In his experiments, Narimousa used the Richardson number as a parameter to determine whether the plume could penetrate the layer. The Richardson number can be calculated by using $R_{\mathrm{i}}=g \Delta \rho / \rho_{\mathrm{o}} h_{\mathrm{o}} /$ $\left(B_{0} R\right)^{2 / 3}$, where $\Delta \rho$ is the change in the density, $h_{\mathrm{o}}$ is the depth of the convective layer and $R$ is the radius of the source. Narimousa (1996) found that for $R_{\mathrm{i}}$ values above 11 , the plume could not penetrate the interface whereas the opposite was true for $R_{\mathrm{i}}$ values below 11 . The $R_{\mathrm{i}}$ has been calculated for each situation in this study (Table 3) and it has been found to be above 11 in all cases except in April 2000, where $R_{\mathrm{i}}$ was 10 . In such a situation, the plume may eventually penetrate the interface.

Previous particle size measurements (Colomer et al., 2001) demonstrated that the turbidity current is $c a 7 \mathrm{~m}$ thick for stations situated between B1 and B2, whereas temperature measurements at the same stations showed that the current is $\mathrm{ca}$ $1 \mathrm{~m}$ thick. Previous work on similar turbidity currents (Parsons et al., 2001; Serra et al., 2002) has attributed the disparity in thickness to double diffusive sedimentation. Other studies (Hill et al., 1998) reveal the importance of flocculation in the settling velocities of particles from turbidity currents. However, this process has been discarded as a possibility in the present study as the particles transported by the turbidity current from the source of B1 to B2 had the same PSD (Fig. 7) with no evidence for the presence of large fastsinking aggregates. Furthermore, the settling velocity of particles within the turbidity current is very small, $8 \times 10^{-5} \mathrm{~m} \mathrm{~s}^{-1}$ (calculated from Stokes law for particles of $10 \mu \mathrm{m}$ diameter). For this reason, it is not expected that Stokes sedimentation could play a significant role in the vertical transport of particles to the lake floor.

Differences in the cores obtained from the northern and southern parts of the lake can be attributed to differences in the sedimentary environment. During the period of lake stratification, the base of the turbidity current was limited by the thermocline that was found at a depth of $c a 10 \mathrm{~m}$.
This is deeper than the shallow sill zone (ca $8 \mathrm{~m}$ ) that connects the southern lobe from the northern lobe of the lake (Fig. 1A). It is likely that the physical conditions of the water column between March and mid-November constrain the hydrothermal plume and the turbidity current to the southern part of the lake, whereas the northern lobe waters do not register the signal of particles from the plume. In contrast, when the lake waters are mixed (from mid-November to February), the plume develops up to the lake surface, spreading throughout the whole lake. In this case, low particle concentrations from the plume could reach the north lobe of the lake and rain out. This finding is consistent with the results found from the sediment traps. Traps situated close to the source of the plume receive more settled particles than traps situated far from the source. This result also agrees with work by Sparks et al. (1991), who found a decrease in the sedimentation rate with distances away from the source of the plume. The expansion and contraction of the plume may produce a continuous sedimentation of silt particles in the zone between basins B1 and B2. Core C1 recovered littoral carbonate deposits characterized by a greater rate of carbonate bioclast production compared with core $\mathrm{C} 2$ records where open lacustrine deposits accumulated in an oxygenated basin. Whereas littoral carbonates are partly broken down into carbonate mud, the openwater basins receive $\mathrm{CaCO}_{3}$ precipitated in the epilimnion plus the silt particles carried by the turbidity current generated from the convective plume rising from basin B1. Intermittent turbidity current activity may have imparted the strong stratification to the deposits between basins B1 and B2 (Canals et al., 1990).

\section{CONCLUSIONS}

In the southern lobe of Lake Banyoles, a particleladen hydrothermal plume has been found to develop from a warm lutocline. In the absence of lake stratification, the plume reaches the surface of the lake. When the lake is stratified, the vertical extent of the plume is limited by stratification in the hypolimnion if the stratification is strong, and by the thermocline if the stratification is weak. Therefore, the thermocline acts as a well-defined obstacle for the vertical development of the plume and confines the turbidity current formed at the equilibrium depth. Both maximum and equilibrium heights of the plume are in accordance with values predicted by conceptual models. 
Results from the particle concentration profiles demonstrate that the plume does not penetrate through the thermocline for $R_{\mathrm{i}}$ larger than 11, also in accordance with previous laboratory results. Differences between the particle concentration and temperature profiles are attributed to a double diffusive sedimentation process from the turbidity current. When the lake is stratified, the turbidity current is confined to the southern lobe of the lake, resulting in higher sedimentation rates. These differences in the sedimentation rates between the two lobes result in different sedimentation records in the cores observed. Finally, the velocities and scales predicted by conceptual models of convection from isolated sources are in accordance with the results presented here. Only the values of the entrainment velocity differ considerably from those measured. This discrepancy has been attributed to two main causes: the confined region of the source of the plume and the vertical constriction of the plume by the thermocline or by the surface of the lake.

\section{ACKNOWLEDGEMENTS}

The authors are grateful to Captain Joan Corominas for his outstanding help and support in this project. The funds for this research were provided by the Direcció General de Recerca, project 1999ACOM 0006, of the Generalitat de Catalunya. We would also like to thank Jeff Parsons and an anonymous reviewer for their reviews of this manuscript, which considerably improved its quality. Finally, we would like to thank Editor Peter Haughton for his final and detailed revision of the manuscript.

\section{LIST OF VARIABLES}

$\begin{array}{ll}A_{\mathrm{p}} & \text { Non-dimensional aspect ratio of the plume } \\ B_{\mathrm{o}} & \text { Total buoyancy flux } \\ D=2 R & \text { Source diameter } \\ f & \text { Coriolis parameter } \\ g & \text { Gravity constant } \\ H & \text { Maximum height of the water column } \\ h_{\mathrm{eq}} & \text { Equilibrium height of the plume } \\ h_{\mathrm{max}} & \text { Maximum height of the plume } \\ h_{\mathrm{o}} & \text { Length scale of the convection } \\ N & \text { Stratification parameter, Brünt-Väisälä } \\ & \text { frequency } \\ N_{\mathrm{v}} & \text { Number of vortices formed by the plume at } \\ R_{\mathrm{i}} & \text { the equilibrium height } \\ R_{\mathrm{o}} & \text { Richardson number } \\ & \text { Rossby plume number }\end{array}$

V

$W_{\mathrm{O}}$

$z_{\mathrm{T}}$

$\alpha$
Rim current velocity at the source

Vertical velocity of the fluid

Depth of the base of the thermocline

Thermal expansion coefficient

\section{REFERENCES}

Baker, E.T., Massoth, G.J. and Feely, R.A. (1987) Cataclysmic hydrothermal venting on the Juan de Fuca Ridge. Nature, 329, 149-151.

Canals, M., Got, H., Julia, R. and Serra, J. (1990) Solutioncollapse depressions and suspensates in the limnocrenic lake of Banyoles (NE Spain). Earth Surf. Proc. Land., 15, 243-254.

Casamitjana, X. and Roget, E. (1993) Resuspension of sediment by focused groundwater in Lake Banyoles. Limnol. Oceanogr., 38, 643-656.

Colomer, J., Ross, J.A. and Casamitjana, X. (1998) Sediment entrainment in karst basins. Aquat. Sci., 60, 338-358.

Colomer, J., Serra, T., Piera, J., Roget, E. and Casamitjana, X. (2001) Observations of a hydrothermal plume in a karstic lake. Limnol. Oceanogr., 46, 197-203.

Colomer, J., Serra, T., Soler, M. and Casamitjana, X. (2002) Sediment fludization events in a lake caused by large monthly rainfalls. Geophys. Res. Lett., 29, DOI: 10.1029/ 2001GL014299.

Dewar, W.K. (2002) Convection in small basins. J. Phys. Oceanogr., 32, 2766-2788.

Fernando, H.J.S., Lee, S.M., Anderson, J., Princevac, M., Pardyjak, E. and Grossman-Clarke, S. (2001) Urban fluid mechanics: air circulation and contaminant dispersion in cities. Environ. Fluid Mech., 1, 107-164.

Gaillard, F. and Desaubies, Y. (1997) A four-dimensional analysis of the thermal structure in the Gulf of Lion. J. Geophys. Res., 102, 12515-12537.

Hill, P.S., Syvitski, J.P., Cowan, E.A. and Powell, R.D. (1998) In situ observations of flow settling velocities in Glacier Bay, Alaska. Mar. Geol., 145, 85-94.

Kristensen, E. and Andersen, F. (1987) Determination of organic carbon in marine sediments: a comparison of two CHN-analyser methods. J. Exp. Mar. Biol. Ecol., 109, $15-23$.

Legg, S. (1996) A heton perspective of baroclinic eddy transfer in localized open ocean circulation. J. Phys. Oceanogr., 26, 2251-2266.

Lu, J., Arya, S.P., Snyder, W.H. and Lawson, R.E. Jr (1997) A laboratory study of the urban heat island in a calm and stably stratified environment. Part I: temperature field. J. Appl. Meteorol., 36, 1377-1391.

Maxworthy, T. (1997) Convection into domains with open boundaries. Annu. Rev. Fluid. Mech., 29, 327-371.

Maxworthy, T. and Narimousa, S. (1994) Unsteady turbulent convection into a homogeneous rotating fluid, with oceanographic applications. J. Phys. Oceanogr., 24, 865887.

Morawitz, W.M.L., Sutton, P.J., Worcester, P.F. and Cornuelle, B.D. (1996) Three-dimensional observations of a deep convective chimney in the greenland sea during winter 1988/89. J. Phys. Oceanogr., 26, 2316-2343.

Moreno-Amich, R. and García-Berthou, E. (1989) A new bathymetric map based on echo-sounding and morphometrical characterization of the Lake of Banyoles (NE-Spain). Hydrobiologia, 185, 83-90. 
Mulder, T. and Alexander, J. (2001) The physical character of subaqueous sedimentary density flows and their deposits. Sedimentology, 48, 269-299.

Narimousa, S. (1996) Penetrative turbulent convection into a rotating two-layer fluid. J. Fluid Mech., 321, 299-313.

Parsons, J.D., Bush, J.W.M. and Sivitski, J.P.M. (2001) Hyperpycnal plume formation from riverine outflows with small sediment concentrations. Sedimentology, 48, 465478.

Sanz, M. (1985) The Hydrogeological System of Banyoles-LaGarrotxa. Quaderns del Centre d'Estudis Comarcals de Banyoles, 1980-1984.

Serra, T., Colomer, J., Gacia, E., Soler, M. and Casamitjana, X. (2002) Effects of a turbid hydrothermal plume on the sedimentation rates in a karstic lake. Geophys. Res. Lett., 29, DOI: 10.1029/2002GL015368.

Sparks, R.S.J., Carey, S.N. and Sirgudsson, H. (1991) Sedimentation from gravity currents generated by turbulent plumes. Sedimentology, 38, 839-856.
Sy, A., Rhein, M., Lazier, J.R.N., Koltermann, K.P., Meincke, J., Putzka, A. and Bersch, M. (1997) Surprisingly rapid spreading of newly formed intermediate waters across the North Atlantic Ocean. Nature, 386, 675-679.

Visbeck, M., Marshall, J. and Jones, H. (1996) Dynamics of isolated convective regions in the ocean. J. Phys. Oceanogr., 26, 1721-1731.

Walker, S.L. and Baker, E.T. (1988) Particle size distributions within hydrothermal plumes over the Juan the Fuca Ridge. Mar. Geol., 78, 217-226.

Whitehead, J.A., Marshall, J. and Hufford, G.E. (1996) Localized convection in rotating stratified fluid. J. Geophys. Res., 101, 25705-25721.

Manuscript received 5 June 2002; revision accepted 16 February 2005 